\title{
Ramona Fotiade, Conceptions of the Absurd From Surrelism to the Existential Thought of Chestov and Fondane
}

\section{Stefano Costa}

\section{(2) OpenEdition}

\section{Journals}

Edizione digitale

URL: https://journals.openedition.org/studifrancesi/38201

DOI: 10.4000/studifrancesi.38201

ISSN: 2421-5856

\section{Editore}

Rosenberg \& Sellier

\section{Edizione cartacea}

Data di pubblicazione: 15 décembre 2004

Paginazione: 643

ISSN: 0039-2944

\section{Notizia bibliografica digitale}

Stefano Costa, «Ramona Fotiade, Conceptions of the Absurd From Surrelism to the Existential Thought of Chestov and Fondane», Studi Francesi [Online], 144 (XLVIII | III) | 2004, online dal 30 novembre 2015, consultato il 08 mai 2021. URL: http://journals.openedition.org/studifrancesi/38201 ; DOI: https:// doi.org/10.4000/studifrancesi.38201

\section{Questo documento è stato generato automaticamente il 8 mai 2021.}

\section{cc)}

Studi Francesi è distribuita con Licenza Creative Commons Attribuzione - Non commerciale - Non opere derivate 4.0 Internazionale. 


\title{
Ramona Fotiade, Conceptions of the Absurd From Surrelism to the Existential Thought of Chestov and Fondane
}

\author{
Stefano Costa
}

\section{NOTIZIA}

RAMONA FOTIADE, Conceptions of the Absurd From Surrelism to the Existential Thought of Chestov and Fondane, Oxford, Legenda, 2001, pp. 259.

1 Questo accurato studio si propone di fornire una presentazione del pensiero esistenziale nell'ambito dei dibattiti filosofici e culturali degli anni '20 e '30 con particolare attenzione al movimento Surrealista. Ripercorrendo il declino della fede religiosa che caratterizzò il periodo tra le due guerre e che, come noto, pervase l'individuo di un sentimento di ritrovata libertà pur alimentando, nel contempo, un malessere innestato sul confronto dell'uomo con il nulla in quella condizione che già Kierkegaard aveva prefigurato sotto il nome di 'ansietà', l'A. rileva come tale sentimento abbia giocato un ruolo fondamentale nelle successive interpretazioni dell'Assurdo elaborate da autori quali Heidegger, Sartre e Camus. Sulla base della documentazione ad oggi disponibile la ricerca dell'A. rileva che il primo tra i filosofi a diffondere in Francia tale concezione fu Léon Chestov il quale mise in luce le affinità esistenti tra il nichilismo russo, del 1860, e la filosofia nietzschiana; pensiero che influenzò profondamente scrittori come Gide, Malraux, Bataille, e molti altri. La letteratura europea, a partire dagli anni ' 30 , trovò espressione in una sempre più tragica visione della condizione umana della quale, i principali punti di riferimento per gli scrittori francesi furono il Surrealismo ed in particolare la "critica esistenziale del discorso razionale' elaborata da Chestov e Benjamin Fondane. Un percorso comparativo, dunque, che colloca scrittori, detti 'dissidenti', come Antonin Artaud, 
Roger Gilbert-Lecomte e René Daumal, in un nuovo contesto intellettuale alla luce dello studio innovativo, forse mai affrontato prima, nel quale l'A. li inserisce. 